Article

\title{
Computing Zagreb Indices and Zagreb Polynomials for Symmetrical Nanotubes
}

\author{
Zehui Shao $^{1}$ (1), Muhammad Kamran Siddiqui ${ }^{2, *(1)}$ and Mehwish Hussain Muhammad ${ }^{3}$ \\ 1 Institute of Computing Science and Technology, Guangzhou University, Guangzhou 510006, China; \\ zshao@gzhu.edu.cn \\ 2 Department of Mathematics, COMSATS University Islamabad, Sahiwal Campus, Sahiwal 57000, Pakistan \\ 3 College of Chemistry and Molecular Engineering, Zhengzhou University, Zhengzhou 450001, China; \\ mehwish@foxmail.com \\ * Correspondence: kamransiddiqui75@gmail.com
}

Received: 26 May 2018; Accepted: 24 June 2018; 28 June 2018

\begin{abstract}
Topological indices are numbers related to sub-atomic graphs to allow quantitative structure-movement/property/danger connections. These topological indices correspond to some specific physico-concoction properties such as breaking point, security, strain vitality of chemical compounds. The idea of topological indices were set up in compound graph hypothesis in view of vertex degrees. These indices are valuable in the investigation of mitigating exercises of specific Nanotubes and compound systems. In this paper, we discuss Zagreb types of indices and Zagreb polynomials for a few Nanotubes covered by cycles.
\end{abstract}

Keywords: first multiple Zagreb index; second multiple Zagreb index, hyper-Zagreb index; Zagreb polynomials; Nanotubes

\section{Introduction}

Mathematical chemistry becomes an interesting branch of science in which we talk about and foresee the concoction structure by utilizing numerical apparatuses and does not really allude to the quantum mechanics. As a branch of numerical science where we apply devices of graph hypothesis, chemical graph theory was introduced and extensively studied to show the compound wonder scientifically. This is more imperative to state that the hydrogen particles are regularly overlooked in any sub-atomic graph. Topological indices are really a numeric measures related to the constitution synthetic material implying for relationship of concoction structure with numerous physio-substance features, compound responsiveness or biological activity. Motivated by the wide applications of topological indices, the topological indices of graphs are studied extensively [1-3].

A nano structure is a question of middle size among both molecular and microscopic structures. Such a material is determined through designing at atomic scale, which is something that has a physical measurement littler than one hundred nanometers, running from bunches of particles to many dimensional layers. Carbon Nanotubes (CNTs) with allotropes of carbon whose shapes are usually hollow and round possess some kinds of nanostructure.

For a graph $G$, the degree of a vertex $w$ is the cardinality of edges incident to $w$ and denoted by $\operatorname{dgr}(s)$. A molecular graph is a basic limited graph in which vertices mean the atoms and edges indicate the compound bonds in fundamental substance structures.

For a graph $G$, a topological index $T p(G)$ is a value which can be obtained by a computing method from $G$. Moreover, if graphs $G$ and $F$ are isomorphic, then the result $T p(F)=T p(G)$ holds. Wiener [4] initially figured out an idea for a topological index in the early years, and at that time, he took a shot at breaking point of paraffin. He defined this record to be the way number. Afterwards, such a 
concept was renamed the Wiener index. As we know, the Wiener record is the first posed index and it is one of the most attractive indices, from not only a hypothetical perspective but applications, and characterized as the total of separations among vertices in $G$, see for subtle elements [5].

The first Zagreb index, a very old topological index, was initiated in 1972 [6] and later many variations of Zagreb index were proposed, e.g., Shirdel et al. [7] in 2013 described a novel index under the name of "hyper-Zagreb index" and it was defined to be

$$
H M(G)=\sum_{s r \in E(G)}[\operatorname{dgr}(s)+\operatorname{dgr}(r)]^{2}
$$

in [8], two new versions of Zagreb indices were put forward, which are the first multiple Zagreb index $P M_{1}(G)$ and the second multiple Zagreb index $P M_{2}(G)$. More precisely, they are formulated as follows.

$$
\begin{aligned}
& P M_{1}(G)=\prod_{s r \in E(G)}[\operatorname{dg} r(s)+\operatorname{dg} r(r)] \\
& P M_{2}(G)=\prod_{s r \in E(G)}[\operatorname{dg} r(s) \times \operatorname{dgr}(r)]
\end{aligned}
$$

Some properties of the indices $P M_{1}(G), P M_{2}(G)$ of specific chemical structures were investigated in [9].

To investigate more interesting properties of $P M_{1}(G), P M_{2}(G)$ of a graph $G$, the first Zagreb Polynomial $M_{1}(G, x)$ and the second Zagreb Polynomial $M_{2}(G, x)$ are proposed $[10,11]$ and put forward as

$$
\begin{aligned}
& M_{1}(G, x)=\sum_{s r \in E(G)} x^{[\operatorname{dgr}(s)+\operatorname{dg} r(r)]} \\
& M_{2}(G, x)=\sum_{s r \in E(G)} x^{[\operatorname{dgr}(s) \times \operatorname{dgr}(r)]}
\end{aligned}
$$

\section{Applications of Nanostructure and Topological Indices}

In the past few decades, graph theory was widely applied as a tool to study physical and chemical properties of materials. More and more people are interested in this field and as a result chemical graph theory was introduces, and later various topological indices were studied and defined. Moreover, as a combination of chemistry, mathematics and nano science, nanotechnology was also studied by means of chemical graph theory. Among these, quantitative structure-activity relationship (QSAR) and quantitative structure-property relationship (QSPR) are analyzed to predict the properties of nanostructure and biological activities. To study QSAR and QSPR, hyper-Zagreb index, first multiple Zagreb index, second multiple Zagreb index and Zagreb polynomials are applied to predict the bioactivity of nanostructures [12-15].

The Zagreb index is defined to be a topological descriptor which is related to substantial synthetic qualities of the atoms [16]. The particle bond network hyper Zagreb index gives a decent connection to the security of direct dendrimers and also the stretched pharmacies and for processing the strain vitality of cyclo alkanes [17-21]. To relate with some physico-concoction properties, multiple Zagreb index bears much preferred prescient control over the prescient energy of the dendrimers [22-24]. The first and second Zagreb indices were revealed to be used to research the $\pi$-electron energy of various microscopic particles [25-27].

\section{3. $H A C_{5} C_{7}[p, q]$ Nanotube}

The $\mathrm{HAC}_{5} C_{7}[p, q]$ Nanotube can be studied as a $C_{5} C_{7}$ net and it consists of $C_{5} \mathrm{~s}$ and $C_{7} \mathrm{~s}$ with the trivalent decorations. An example is presented in Figure 1, which can be decorated in a cylindrical or toroidal manner. The 2-dimensional lattice of $H_{A C} C_{5} C_{7}[p, q]$ were ever been discussed in [28], in 
which $p$ and $q$ are the cardinalites of heptagons in one row and periods in whole lattice, respectively. As an example, such a Nanotube with three rows is presented in Figure 2.

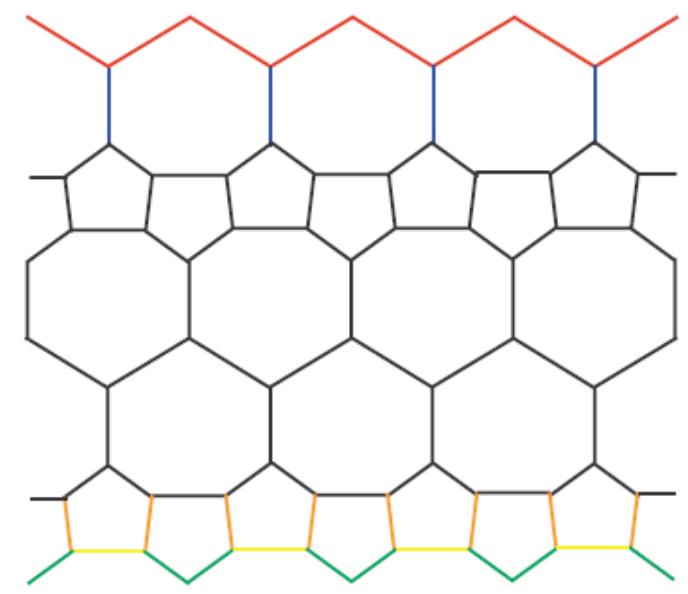

Figure 1. $H A C_{5} C_{7}[p, q]$ Nanotube with $p=4$ and $q=2$.

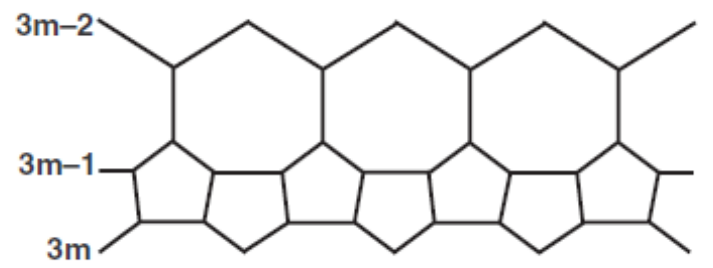

Figure 2. The $m$ th period of $H A C_{5} C_{7}[p, q]$ Nanotube.

\subsection{Methodology of $\mathrm{HAC}_{5} \mathrm{C}_{7}[p, q]$ Nanotube Formulas}

In the Nanotube $\operatorname{HAC}_{5} C_{7}[p, q],(p, q \geq 1)$, we have that $V\left(H A C_{5} C_{7}[p, q]\right)=8 p q+p$ and $E\left(H A C_{5} C_{7}[p, q]\right)=12 p q-p$. The cardinality of vertices of degree two and three are $2 p+2$ and $8 p q-p-2$, respectively. According to their sum the the degree over its neighbors of each vertex, the edge set can be partitioned to six disjoint sets as follows.

$$
\begin{aligned}
& E_{1}\left(H A C_{5} C_{7}[p, q]\right)=\left\{s r \in E\left(H A C_{5} C_{7}[p, q]\right) \mid \operatorname{dgr}(s)=6, \operatorname{dgr}(r)=7\right\} \\
& E_{2}\left(H A C_{5} C_{7}[p, q]\right)=\left\{s r \in E\left(H A C_{5} C_{7}[p, q]\right) \mid \operatorname{dgr}(s)=6, \operatorname{dg} r(r)=8\right\} \\
& E_{3}\left(H A C_{5} C_{7}[p, q]\right)=\left\{s r \in E\left(H A C_{5} C_{7}[p, q]\right) \mid \operatorname{dgr}(s)=7, \operatorname{dgr}(r)=9\right\} \\
& E_{4}\left(H A C_{5} C_{7}[p, q]\right)=\left\{s r \in E\left(H A C_{5} C_{7}[p, q]\right) \mid \operatorname{dgr}(s)=8, \operatorname{dg} r(r)=8\right\} \\
& E_{5}\left(H A C_{5} C_{7}[p, q]\right)=\left\{s r \in E\left(H A C_{5} C_{7}[p, q]\right) \mid \operatorname{dgr}(s)=8, \operatorname{dgr}(r)=9\right\} \\
& E_{6}\left(H A C_{5} C_{7}[p, q]\right)=\left\{s r \in E\left(H A C_{5} C_{7}[p, q]\right) \mid \operatorname{dgr}(s)=9, \operatorname{dgr}(r)=9\right\}
\end{aligned}
$$

The cardinality of edges in $E_{1}\left(H A C_{5} C_{7}[p, q]\right), E_{2}\left(H A C_{5} C_{7}[p, q]\right)$ and $E_{5}\left(H A C_{5} C_{7}[p, q]\right)$ are $2 p$. The cardinality of edges in $E_{3}\left(H A C_{5} C_{7}[p, q]\right)$ and $E_{4}\left(H A C_{5} C_{7}[p, q]\right)$ are $p$. The cardinality of edges in $E_{6}\left(H A C_{5} C_{7}[p, q]\right)$ is $12 p q-9 p$. Such a partition is shown in Figure 1 in which red, green, blue, yellow, brown and black edges are the edges belong to $E_{1}\left(H A C_{5} C_{7}[p, q]\right), E_{2}\left(H A C_{5} C_{7}[p, q]\right)$, $E_{3}\left(H A C_{5} C_{7}[p, q]\right), E_{4}\left(H A C_{5} C_{7}[p, q]\right), E_{5}\left(H A C_{5} C_{7}[p, q]\right)$ and $E_{6}\left(H A C_{5} C_{7}[p, q]\right)$ respectively.

\subsection{Main Results for $\mathrm{HAC}_{5} \mathrm{C}_{7}[p, q]$ Nanotube}

In this section, we will obtain hyper-Zagreb index $H M(G)$, first multiple Zagreb index $P M_{1}(G)$, second multiple Zagreb index $P M_{2}(G)$, Zagreb polynomials $M_{1}(G, x), M_{2}(G, x)$ for $\mathrm{HAC}_{5} C_{7}[p, q],(p, q \geq 1)$ Nanotube. 


\section{- Hyper Zagreb index of $H A C_{5} C_{7}[p, q]$ Nanotube}

Let $G$ be the $H_{A C} C_{5} C_{7}[p, q]$ Nanotube. Then by Equations (1), we have

$$
\begin{aligned}
H M(G) & =\sum_{s r \in E(G)}[\operatorname{dg} r(s)+\operatorname{dg} r(r)]^{2} \\
H M(G) & =\sum_{s r \in E_{1}}[\operatorname{dg} r(s)+\operatorname{dg} r(r)]^{2}+\sum_{s r \in E_{2}}[\operatorname{dgr}(s)+\operatorname{dg} r(r)]^{2}+\sum_{s r \in E_{3}}[\operatorname{dgr}(s)+\operatorname{dg} r(r)]^{2} \\
& +\sum_{s r \in E_{4}}[\operatorname{dg} r(s)+\operatorname{dg} r(r)]^{2}+\sum_{s r \in E_{5}}[\operatorname{dgr}(s)+\operatorname{dg} r(r)]^{2}+\sum_{s r \in E_{6}}[\operatorname{dg} r(s)+\operatorname{dg} r(r)]^{2} \\
& =13^{2}\left|E_{1}\right|+14^{2}\left|E_{2}\right|+16^{2}\left|E_{3}\right|+16^{2}\left|E_{4}\right|+17^{2}\left|E_{5}\right|+18^{2}\left|E_{6}\right| \\
& =169(2 p)+196(2 p)+256 p+256 p+289(2 p)+324(12 p q-9 p)=3888 p q-1092 p
\end{aligned}
$$

\section{- Multiple Zagreb indices of $H A C_{5} C_{7}[p, q]$ Nanotube}

Let $G$ be the $H A C_{5} C_{7}[p, q]$ Nanotube. Then by Equations (2) and (3), we have

$$
\begin{aligned}
P M_{1}(G) & =\prod_{s r \in E(G)}[\operatorname{dgr}(s)+\operatorname{dg} r(r)] \\
P M_{1}(G) & =\prod_{s r \in E_{1}}[\operatorname{dgr}(s)+\operatorname{dg} r(r)] \times \prod_{s r \in E_{2}}[\operatorname{dgr}(s)+\operatorname{dg} r(r)] \times \prod_{s r \in E_{3}}[\operatorname{dgr}(s)+\operatorname{dg} r(r)] \\
& \times \prod_{s r \in E_{4}}[\operatorname{dgr}(s)+\operatorname{dg} r(r)] \times \prod_{s r \in E_{5}}[\operatorname{dgr}(s)+\operatorname{dg} r(r)] \times \prod_{s r \in E_{6}}[\operatorname{dgr}(s)+\operatorname{dg} r(r)] \\
& =13^{\left|E_{1}\right|} \times 14^{\left|E_{2}\right|} \times 16^{\left|E_{3}\right|} \times 16^{\left|E_{4}\right|} \times 17^{\left|E_{5}\right|} \times 18^{\left|E_{6}\right|} \\
& =13^{2 p} \times 14^{2 p} \times 16^{p} \times 16^{p} \times 17^{2 p} \times 18^{(12 p q-9 p)} \\
P M_{2}(G) & =\prod_{s r \in E(G)}[\operatorname{dgr}(s) \times \operatorname{dgr}(r)] \\
P M_{2}(G) & =\prod_{s r \in E_{1}}[\operatorname{dgr}(s) \times \operatorname{dgr}(r)] \times \prod_{s r \in E_{2}}[\operatorname{dgr}(s) \times \operatorname{dgr}(r)] \times \prod_{s r \in E_{3}}[\operatorname{dgr}(s) \times \operatorname{dgr}(r)] \\
& \times \prod_{s r \in E_{4}}[\operatorname{dgr}(s) \times \operatorname{dgr}(r)] \times \prod_{s r \in E_{5}}[\operatorname{dgr}(s) \times \operatorname{dgr}(r)] \times \prod_{s r \in E_{6}}[\operatorname{dgr}(s) \times \operatorname{dgr}(r)] \\
& =42^{\left|E_{1}\right|} \times 48^{\left|E_{2}\right|} \times 63^{\left|E_{3}\right|} \times 64^{\left|E_{4}\right|} \times 72^{\left|E_{5}\right|} \times 81^{\left|E_{6}\right|} \\
& =42^{2 p} \times 48^{2 p} \times 63^{p} \times 64^{p} \times 72^{2 p} \times 81^{(12 p q-9 p)}
\end{aligned}
$$

\section{- Zagreb Polynomials of $H A C_{5} C_{7}[p, q]$ Nanotube}

Let $G$ be the $H A C_{5} C_{7}[p, q]$ Nanotube. Then by Equations (4) and (5), we have

$$
\begin{aligned}
M_{1}(G, x) & =\sum_{s r \in E(G)} x^{[\operatorname{dgr}(s)+\operatorname{dg} r(r)]} \\
M_{1}(G, x) & =\sum_{s r \in E_{1}} x^{[\operatorname{dgr}(s)+\operatorname{dgr}(r)]}+\sum_{s r \in E_{2}} x^{[\operatorname{dgr}(s)+\operatorname{dgr}(r)]}+\sum_{s r \in E_{3}} x^{[\operatorname{dgr} r(s)+\operatorname{dg} r(r)]} \\
& +\sum_{s r \in E_{4}} x^{[\operatorname{dgr}(s)+\operatorname{dgr}(r)]}+\sum_{s r \in E_{5}} x^{[\operatorname{dgr}(s)+\operatorname{dgr}(r)]}+\sum_{s r \in E_{6}} x^{[\operatorname{dg} r(s)+\operatorname{dg} r(r)]} \\
& =\sum_{s r \in E_{1}} x^{13}+\sum_{s r \in E_{2}} x^{14}+\sum_{s r \in E_{3}} x^{16}+\sum_{s r \in E_{4}} x^{16}+\sum_{s r \in E_{5}} x^{17}+\sum_{s r \in E_{6}} x^{18} \\
& =\left|E_{1}\right| x^{13}+\left|E_{2}\right| x^{14}+\left|E_{3}\right| x^{16}+\left|E_{4}\right| x^{16}+\left|E_{5}\right| x^{17}+\left|E_{6}\right| x^{18} \\
& =2 p x^{13}+2 p x^{14}+p x^{16}+p x^{16}+2 p x^{17}+(12 p q-9 p) x^{18}
\end{aligned}
$$




$$
\begin{aligned}
M_{2}(G, x) & =\sum_{s r \in E(G)} x^{[\operatorname{dg} r(s) \times \operatorname{dgr}(r)]} \\
M_{2}(G, x) & =\sum_{s r \in E_{1}} x^{[\operatorname{dgr}(s) \times \operatorname{dgr}(r)]}+\sum_{s r \in E_{2}} x^{[\operatorname{dgr} r(s) \times \operatorname{dgr}(r)]}+\sum_{s r \in E_{3}} x^{[\operatorname{dgr}(s) \times \operatorname{dg} r(r)]} \\
& +\sum_{s r \in E_{4}} x^{[\operatorname{dgr}(s) \times \operatorname{dgr}(r)]}+\sum_{s r \in E_{5}} x^{[\operatorname{dg} r(s) \times \operatorname{dgr}(r)]}+\sum_{s r \in E_{6}} x^{[\operatorname{dg} r(s) \times \operatorname{dgr}(r)]} \\
& =\sum_{s r \in E_{1}} x^{42}+\sum_{s r \in E_{2}} x^{48}+\sum_{s r \in E_{3}} x^{63}+\sum_{s r \in E_{4}} x^{64}+\sum_{s r \in E_{5}} x^{72}+\sum_{s r \in E_{6}} x^{81} \\
& =\left|E_{1}\right| x^{42}+\left|E_{2}\right| x^{48}+\left|E_{3}\right| x^{63}+\left|E_{4}\right| x^{64}+\left|E_{5}\right| x^{72}+\left|E_{6}\right| x^{81} \\
& =2 p x^{42}+2 p x^{48}+p x^{63}+p x^{64}+2 p x^{72}+(12 p q-9 p) x^{81}
\end{aligned}
$$

\section{4. $H A C_{5} C_{6} C_{7}[p, q]$ Nanotube}

The $H_{A} C_{5} C_{6} C_{7}[p, q]$ Nanotube is a $C_{5} C_{6} C_{7}$ net and constructed by using $C_{5} s, C_{6} s$ and $C_{7} s$ alternately with the trivalent decorations as demonstrated in Figure 3 . These tessellations of $C_{5} s, C_{6} s$ and $C_{7} S$ are usually decorated in a cylindrical or a torodial manner. The 2-dimensional lattice of $H A C_{5} C_{6} C_{7}[p, q]$ is obtained by repeating pentagons for $q$ rows and $p$ columns. The construction of this Nanotube can be found in [29]. As an example, a Nanotube with three rows is shown in Figure 4.

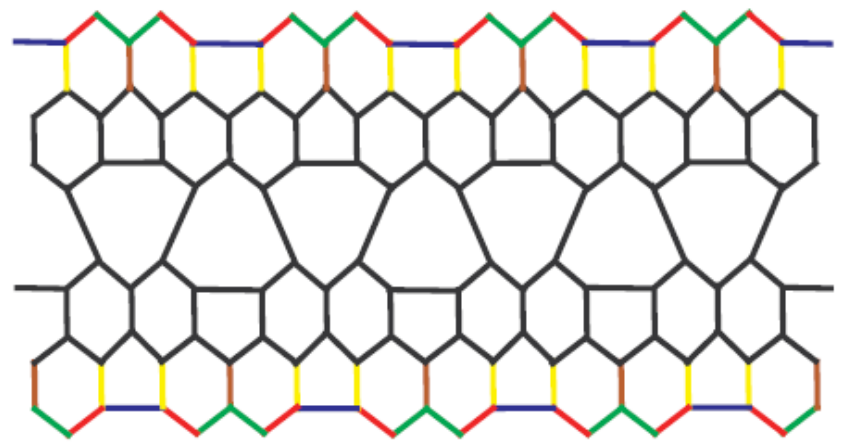

Figure 3. $H A C_{5} C_{6} C_{7}[p, q]$ Nanotube with $p=4$ and $q=2$.

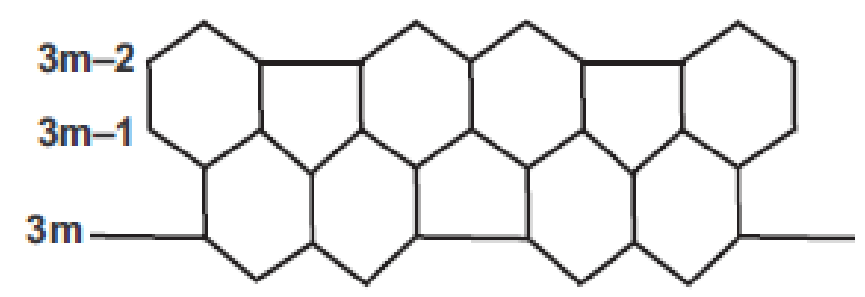

Figure 4. The $m$ th period of $H A C_{5} C_{6} C_{7}[p, q]$ Nanotube.

\subsection{Methodology of Carbon Graphite $\mathrm{HAC}_{5} \mathrm{C}_{6} \mathrm{C}_{7}[p, q]$ Formulas}

For the Nanotube $H A C_{5} C_{6} C_{7}[p, q],(p, q \geq 1)$ (see Figure 2), we have $V\left(H A C_{5} C_{6} C_{7}[p, q]\right)=$ $8 p q+p$ and $E\left(H A C_{5} C_{6} C_{7}[p, q]\right)=12 p q-p$, and its edge set can be partitioned as follows.

$E_{1}\left(H A C_{5} C_{6} C_{7}[p, q]\right)=\left\{s r \in E\left(H A C_{5} C_{6} C_{7}[p, q]\right) \mid \operatorname{dgr}(s)=6, \operatorname{dgr}(r)=7\right\}$

$E_{2}\left(H A C_{5} C_{6} C_{7}[p, q]\right)=\left\{s r \in E\left(H A C_{5} C_{6} C_{7}[p, q]\right) \mid \operatorname{dgr}(s)=6, \operatorname{dg} r(r)=8\right\}$

$E_{3}\left(H A C_{5} C_{6} C_{7}[p, q]\right)=\left\{s r \in E\left(H A C_{5} C_{6} C_{7}[p, q]\right) \mid \operatorname{dgr}(s)=7, \operatorname{dgr}(r)=8\right\}$

$E_{4}\left(H A C_{5} C_{6} C_{7}[p, q]\right)=\left\{s r \in E\left(H A C_{5} C_{6} C_{7}[p, q]\right) \mid \operatorname{dgr}(s)=8, \operatorname{dgr}(r)=8\right\}$

$E_{5}\left(H A C_{5} C_{6} C_{7}[p, q]\right)=\left\{s r \in E\left(H A C_{5} C_{6} C_{7}[p, q]\right) \mid \operatorname{dgr}(s)=8, \operatorname{dgr}(r)=9\right\}$

$E_{6}\left(H A C_{5} C_{6} C_{7}[p, q]\right)=\left\{s r \in E\left(H A C_{5} C_{6} C_{7}[p, q]\right) \mid \operatorname{dgr}(s)=9, \operatorname{dgr}(r)=9\right\}$

The cardinality of edges in $E_{1}\left(H A C_{5} C_{6} C_{7}[p, q]\right), E_{2}\left(H A C_{5} C_{6} C_{7}[p, q]\right)$ and $E_{5}\left(H A C_{5} C_{6} C_{7}[p, q]\right)$ are $4 p$, the cardinality of edges in $E_{3}\left(H A C_{5} C_{6} C_{7}[p, q]\right)$ and $E_{4}\left(H A C_{5} C_{6} C_{7}[p, q]\right)$ are $2 p$ while the 
cardinality of edges in $E_{6}\left(H A C_{5} C_{6} C_{7}[p, q]\right)$ are $24 p q-18 p$. The representatives of these partitioned edge set are demonstrated in Figure 3, in which the edge set with color green, red, brown, blue, yellow and black are $E_{1}\left(H A C_{5} C_{6} C_{7}[p, q]\right), E_{2}\left(H A C_{5} C_{6} C_{7}[p, q]\right), E_{3}\left(H A C_{5} C_{6} C_{7}[p, q]\right), E_{4}\left(H A C_{5} C_{6} C_{7}[p, q]\right)$, $E_{5}\left(H A C_{5} C_{6} C_{7}[p, q]\right)$ and $E_{6}\left(H A C_{5} C_{6} C_{7}[p, q]\right)$ respectively.

\subsection{Main Results for $\mathrm{HAC}_{5} \mathrm{C}_{6} \mathrm{C}_{7}[p, q]$ Nanotube}

In this section, we derive hyper-Zagreb index $H M$, first multiple Zagreb index $P M_{1}$, second multiple Zagreb index $P M_{2}$ and Zagreb polynomials for $H A C_{5} C_{6} C_{7}[p, q]$ Nanotube.

\section{- Hyper Zagreb index of $H_{A} C_{5} C_{6} C_{7}[p, q]$ Nanotube}

Let $G$ be the $H A C_{5} C_{6} C_{7}[p, q]$ Nanotube. Then by Equation (1), we have

$$
\begin{aligned}
H M(G) & =\sum_{s r \in E(G)}[\operatorname{dg} r(s)+\operatorname{dg} r(r)]^{2} \\
H M(G) & =\sum_{s r \in E_{1}}[\operatorname{dgr}(s)+\operatorname{dg} r(r)]^{2}+\sum_{s r \in E_{2}}[\operatorname{dgr}(s)+\operatorname{dg} r(r)]^{2}+\sum_{s r \in E_{3}}[\operatorname{dgr}(s)+\operatorname{dg} r(r)]^{2} \\
& +\sum_{s r \in E_{4}}[\operatorname{dg} r(s)+\operatorname{dg} r(r)]^{2}+\sum_{s r \in E_{5}}[\operatorname{dg} r(s)+\operatorname{dg} r(r)]^{2}+\sum_{s r \in E_{6}}[\operatorname{dg} r(s)+\operatorname{dg} r(r)]^{2} \\
& =13^{2}\left|E_{1}\right|+14^{2}\left|E_{2}\right|+15^{2}\left|E_{3}\right|+16^{2}\left|E_{4}\right|+17^{2}\left|E_{5}\right|+18^{2}\left|E_{6}\right| \\
& =169(4 p)+196(4 p)+225(2 p)+256(2 p)+289(4 p)+324(24 p q-18 p) \\
& =7776 p q-2254 p
\end{aligned}
$$

\section{- $\quad$ Multiple Zagreb indices of $H A C_{5} C_{6} C_{7}[p, q]$ Nanotube}

Let $G$ be the $H A C_{5} C_{6} C_{7}[p, q]$ Nanotube. Then by Equations (2) and (3), we have

$$
\begin{aligned}
P M_{1}(G) & =\prod_{s r \in E(G)}[\operatorname{dgr}(s)+\operatorname{dg} r(r)] \\
P M_{1}(G) & =\prod_{s r \in E_{1}}[\operatorname{dgr}(s)+d g r(r)] \times \prod_{s r \in E_{2}}[\operatorname{dgr}(s)+\operatorname{dgr}(r)] \times \prod_{s r \in E_{3}}[\operatorname{dgr}(s)+\operatorname{dgr}(r)] \\
& \times \prod_{s r \in E_{4}}[\operatorname{dgr}(s)+d g r(r)] \times \prod_{s r \in E_{5}}[\operatorname{dgr}(s)+\operatorname{dgr} r(r)] \times \prod_{s r \in E_{6}}[\operatorname{dgr}(s)+\operatorname{dgr}(r)] \\
& =13^{\left|E_{1}\right|} \times 14^{\left|E_{2}\right|} \times 15^{\left|E_{3}\right|} \times 16^{\left|E_{4}\right|} \times 17^{\left|E_{5}\right|} \times 18^{\left|E_{6}\right|} \\
& =13^{4 p} \times 14^{4 p} \times 15^{2 p} \times 16^{2 p} \times 17^{4 p} \times 18^{(24 p q-18 p)} \\
P M_{2}(G) & =\prod_{s r \in E(G)}[\operatorname{dgr}(s) \times \operatorname{dgr}(r)] \\
P M_{2}(G) & =\prod_{s r \in E_{1}}[\operatorname{dgr}(s) \times d g r(r)] \times \prod_{s r \in E_{2}}[\operatorname{dgr}(s) \times \operatorname{dgr}(r)] \times \prod_{s r \in E_{3}}[\operatorname{dgr}(s) \times \operatorname{dgr}(r)] \\
& \times \prod_{s r \in E_{4}}[\operatorname{dgr}(s) \times d g r(r)] \times \prod_{s r \in E_{5}}[\operatorname{dgr}(s) \times \operatorname{dgr}(r)]+\prod_{s r \in E_{6}}[\operatorname{dgr}(s) \times \operatorname{dgr}(r)] \\
& =42^{\left|E_{1}\right|} \times 48^{\left|E_{2}\right|} \times 56^{\left|E_{3}\right|} \times 64^{\left|E_{4}\right|} \times 72^{\left|E_{5}\right|} \times 81^{\left|E_{6}\right|} \\
& =42^{4 p} \times 48^{4 p} \times 56^{2 p} \times 64^{2 p} \times 72^{4 p} \times 81^{(24 p q-18 p)}
\end{aligned}
$$




\section{- Zagreb polynomials of $H A C_{5} C_{6} C_{7}[p, q]$ Nanotube}

Let $G$ be the graph of $H A C_{5} C_{6} C_{7}[p, q]$ Nanotube. Then by Equations (4) and (5), we have

$$
\begin{aligned}
& M_{1}(G, x)=\sum_{s r \in E(G)} x^{[\operatorname{dgr}(s)+\operatorname{dgr}(r)]} \\
& M_{1}(G, x)=\sum_{s r \in E_{1}} x^{[\operatorname{dgr}(s)+\operatorname{dgr}(r)]}+\sum_{s r \in E_{2}} x^{[\operatorname{dgr}(s)+\operatorname{dgr}(r)]}+\sum_{s r \in E_{3}} x^{[\operatorname{dgr}(s)+\operatorname{dgr}(r)]} \\
& +\sum_{s r \in E_{4}} x^{[\operatorname{dgr}(s)+\operatorname{dgr}(r)]}+\sum_{s r \in E_{5}} x^{[\operatorname{dgr}(s)+\operatorname{dgr}(r)]}+\sum_{s r \in E_{6}} x^{[\operatorname{dgr}(s)+\operatorname{dgr}(r)]} \\
& =\sum_{s r \in E_{1}} x^{13}+\sum_{s r \in E_{2}} x^{14}+\sum_{s r \in E_{3}} x^{16}+\sum_{s r \in E_{4}} x^{16}+\sum_{s r \in E_{5}} x^{17}+\sum_{s r \in E_{6}} x^{18} \\
& =\left|E_{1}\right| x^{13}+\left|E_{2}\right| x^{14}+\left|E_{3}\right| x^{15}+\left|E_{4}\right| x^{16}+\left|E_{5}\right| x^{17}+\left|E_{6}\right| x^{18} \\
& =4 p x^{13}+4 p x^{14}+2 p x^{15}+2 p x^{16}+4 p x^{17}+(24 p q-18 p) x^{18} \\
& M_{2}(G, x)=\sum_{s r \in E(G)} x^{[\operatorname{dgr}(s) \times \operatorname{dgr}(r)]} \\
& M_{2}(G, x)=\sum_{s r \in E_{1}} x^{[\operatorname{dgr}(s) \times \operatorname{dgr}(r)]}+\sum_{s r \in E_{2}} x^{[\operatorname{dgr}(s) \times \operatorname{dgr}(r)]}+\sum_{s r \in E_{3}} x^{[\operatorname{dgr} r(s) \times \operatorname{dgr}(r)]} \\
& +\sum_{s r \in E_{4}} x^{[\operatorname{dgr} r(s) \times \operatorname{dgr}(r)]}+\sum_{s r \in E_{5}} x^{[\operatorname{dgr} r(s) \times \operatorname{dg} r(r)]}+\sum_{s r \in E_{6}} x^{[\operatorname{dgr} r(s) \times d g r(r)]} \\
& =\sum_{s r \in E_{1}} x^{42}+\sum_{s r \in E_{2}} x^{48}+\sum_{s r \in E_{3}} x^{56}+\sum_{s r \in E_{4}} x^{64}+\sum_{s r \in E_{5}} x^{72}+\sum_{s r \in E_{6}} x^{81} \\
& =\left|E_{1}\right| x^{42}+\left|E_{2}\right| x^{48}+\left|E_{3}\right| x^{56}+\left|E_{4}\right| x^{64}+\left|E_{5}\right| x^{72}+\left|E_{6}\right| x^{81} \\
& =4 p x^{42}+4 p x^{48}+2 p x^{56}+2 p x^{64}+4 p x^{72}+(24 p q-18 p) x^{81}
\end{aligned}
$$

\section{5. $T U C_{4} C_{8}[p, q]$ Nanotube and Nanotorus}

We will use the notations and notions of Diudea and Graovac, and the 2D lattice of $\operatorname{TUC}_{4} C_{8}[p, q]$ Nanotorus is denoted by KTUC $[p, q]$ (see Figure 5) and the $T U C_{4} C_{8}[p, q]$ Nanotube is denoted by GTUC $[p, q]$ (see Figure 6). A TUC $C_{4} C_{8}[p, q]$ Nanotube is constructed in such a way that the total cardinality of octagons in each row equalsp $p$ and the total cardinality of octagons in each column equals $q$. An example is presented in Figure 6. In $T U C_{4} C_{8}[p, q]$ Nanotube, the total cardinality of octagons and squares are the same as those in each row, and in $T U C_{4} C_{8}[p, q]$ Nanotorus the total cardinality of octagons and squares are the same as those in each row and column. In 2D lattice of $\mathrm{TUC}_{4} \mathrm{C}_{8}[p, q]$ Nanotorus, the total cardinality of squares in rows and columns are $(p+1)$ and $(q+1)$, respectively (cf. [30,31]).

The cardinalities of the vertex and edge set of $\operatorname{KTUC}[p, q]$ and $\operatorname{GTUC}[p, q]$ are presented in the following Table 1.

Table 1. Order and size of Nanotorus $\operatorname{KTUC}[p, q]$ and Nanotube GTUC $[p, q]$.

\begin{tabular}{ccc}
\hline TUC $_{4} C_{8}[p, q]$ & KTUC $[p, q]$ & GTUC $[p, q]$ \\
\hline$|V|$ & $\left(4 p^{2}+4 p\right)(q+1)$ & $4 p q+4 p$ \\
$|E|$ & $6 p q+5 p+5 q+4$ & $6 p q+5 p$ \\
\hline
\end{tabular}




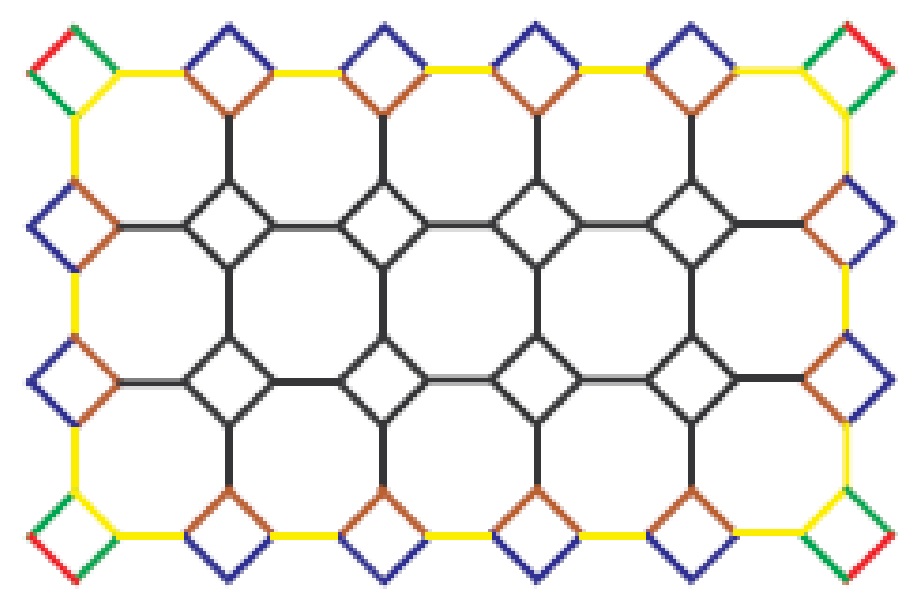

Figure 5. 2D-lattice of $\mathrm{TUC}_{4} \mathrm{C}_{8}(R)[p, q]$ Nanotorus with $p=5$ and $q=3$.

\subsection{Methodology of KTUC $[p, q],(p, q \geq 1)$ Nanotorus Formulas}

For the Nanotorus KTUC $[p, q],(p, q \geq 1)$, we have that the number of vertices in $\operatorname{KTUC}[p, q]$ is $4 p(p+1)(q+1)$ and the number of edges is $6 p q+5(p+q)+4$. The edge set can be partitioned into the following six disjoint sets:

$$
\begin{aligned}
& E_{1}(\operatorname{KTUC}[p, q])=\{s r \in E(\operatorname{KTUC}[p, q]) \mid \operatorname{dgr}(s)=5, \operatorname{dgr}(r)=5\} \\
& E_{2}(\operatorname{KTUC}[p, q])=\{s r \in E(\operatorname{KTUC}[p, q]) \mid \operatorname{dgr}(s)=5, \operatorname{dgr}(r)=8\} \\
& E_{3}(\operatorname{KTUC}[p, q])=\{s r \in E(\operatorname{KTUC}[p, q]) \mid \operatorname{dgr}(s)=6, \operatorname{dgr}(r)=8\} \\
& E_{4}(\operatorname{KTUC}[p, q])=\{s r \in E(\operatorname{KTUC}[p, q]) \mid \operatorname{dgr}(s)=8, \operatorname{dg} r(r)=8\} \\
& E_{5}(\operatorname{KTUC}[p, q])=\{s r \in E(\operatorname{KTUC}[p, q]) \mid \operatorname{dgr}(s)=8, \operatorname{dgr}(r)=9\} \\
& E_{6}(\operatorname{KTUC}[p, q])=\{s r \in E(\operatorname{KTUC}[p, q]) \mid \operatorname{dgr}(s)=9, \operatorname{dgr}(r)=9\}
\end{aligned}
$$

We can obtain that $\left|E_{1}(\operatorname{KTUC}[p, q])\right|=4,\left|E_{2}(\operatorname{KTUC}[p, q])\right|=8,\left|E_{3}(\operatorname{KTUC}[p, q])\right|=4(p+$ $q-2),\left|E_{4}(\operatorname{KTUC}[p, q])\right|=2(p+q+2),\left|E_{5}(\operatorname{KTUC}[p, q])\right|=4(p+q-2)$ and $\left|E_{6}(\operatorname{KTUC}[p, q])\right|=$ $6 p q-5 p-5 q+4$, and the representatives of these partitioned edge set are demonstrated in Figure 5, in which the edge set with color red, green, blue, yellow, brown and black are $E_{1}(\operatorname{KTUC}[p, q])$, $E_{2}(K T U C[p, q]), E_{3}(K T U C[p, q]), E_{4}(K T U C[p, q]), E_{5}(K T U C[p, q])$ and $E_{6}(K T U C[p, q])$ respectively.

\subsection{Main Results for KTUC $[p, q],(p, q \geq 1)$ Nanotorus}

\section{- Hyper Zagreb index of KTUC $[p, q],(p, q \geq 1)$ Nanotorus}

Let $G=\operatorname{KTUC}[p, q]$. Now using Equation (1), we have

$$
\begin{aligned}
H M(G) & =\sum_{s r \in E(G)}[\operatorname{dgr}(s)+\operatorname{dg} r(r)]^{2} \\
H M(K) & =\sum_{s r \in E_{1}}[\operatorname{dg} r(s)+\operatorname{dg} r(r)]^{2}+\sum_{s r \in E_{2}}[\operatorname{dgr} r(s)+\operatorname{dg} r(r)]^{2}+\sum_{s r \in E_{3}}[\operatorname{dg} r(s)+\operatorname{dg} r(r)]^{2} \\
& +\sum_{s r \in E_{4}}[\operatorname{dgr}(s)+\operatorname{dg} r(r)]^{2}+\sum_{s r \in E_{5}}[\operatorname{dgr}(s)+\operatorname{dg} r(r)]^{2}+\sum_{s r \in E_{6}}[\operatorname{dg} r(s)+\operatorname{dg} r(r)]^{2} \\
& =10^{2}\left|E_{1}\right|+13^{2}\left|E_{2}\right|+14^{2}\left|E_{3}\right|+16^{2}\left|E_{4}\right|+17^{2}\left|E_{5}\right|+18^{2}\left|E_{6}\right| \\
& =100(4)+169(8)+196(4 p+4 q-8)+256(2 p+2 q+4) \\
& +289(4 p+4 q-8)+324(6 p q-5 p-5 q+4) \\
& =1944 p q+832(p+q)+192
\end{aligned}
$$


- Multiple Zagreb indices of $K T U C[p, q],(p, q \geq 1)$ Nanotorus

Let $G=K T U C[p, q]$. Now using Equations (2) and (3) we have

$$
\begin{aligned}
& P M_{1}(G)=\prod_{s r \in E(G)}[\operatorname{dgr}(s)+\operatorname{dgr}(r)] \\
& P M_{1}(K)=\prod_{s r \in E_{1}}[\operatorname{dgr}(s)+\operatorname{dg} r(r)] \times \prod_{s r \in E_{2}}[\operatorname{dg} r(s)+\operatorname{dg} r(r)] \times \prod_{s r \in E_{3}}[\operatorname{dgr}(s)+\operatorname{dg} r(r)] \\
& \times \prod_{s r \in E_{4}}[\operatorname{dgr}(s)+\operatorname{dgr}(r)] \times \prod_{s r \in E_{5}}[\operatorname{dgr}(s)+\operatorname{dgr}(r)] \times \prod_{s r \in E_{6}}[\operatorname{dgr}(s)+\operatorname{dgr}(r)] \\
& =10^{\left|E_{1}\right|} \times 13^{\left|E_{2}\right|} \times 14^{\left|E_{3}\right|} \times 16^{\left|E_{4}\right|} \times 17^{\left|E_{5}\right|} \times 18^{\left|E_{6}\right|} \\
& =10^{4} \times 13^{8} \times 14^{(4 p+4 q-8)} \times 16^{(2 p+2 q+4)} \times 17^{(4 p+4 q-8)} \times 18^{(6 p q-5 p-5 q+4)} \\
& P M_{2}(G)=\prod_{s r \in E(G)}[\operatorname{dgr} r(s) \times \operatorname{dgr}(r)] \\
& P M_{2}(K)=\prod_{s r \in E_{1}}[\operatorname{dgr}(s) \times \operatorname{dg} r(r)] \times \prod_{s r \in E_{2}}[\operatorname{dg} r(s) \times \operatorname{dg} r(r)] \times \prod_{s r \in E_{3}}[\operatorname{dg} r(s) \times \operatorname{dg} r(r)] \\
& \times \prod_{s r \in E_{4}}[\operatorname{dgr}(s) \times \operatorname{dgr}(r)] \times \prod_{s r \in E_{5}}[\operatorname{dgr}(s) \times \operatorname{dgr}(r)] \times \prod_{s r \in E_{6}}[\operatorname{dgr}(s) \times \operatorname{dgr}(r)] \\
& =25^{\left|E_{1}\right|} \times 40^{\left|E_{2}\right|} \times 48^{\left|E_{3}\right|} \times 64^{\left|E_{4}\right|} \times 72^{\left|E_{5}\right|} \times 81^{\left|E_{6}\right|} \\
& =25^{4} \times 40^{8} \times 48^{(4 p+4 q-8)} \times 64^{(2 p+2 q+4)} \times 72^{(4 p+4 q-8)} \times 81^{(6 p q-5 p-5 q+4)}
\end{aligned}
$$

- Zagreb polynomials of KTUC $[p, q],(p, q \geq 1)$ Nanotorus

Let $G=\operatorname{KTUC}[p, q]$. Now using Equations (4) and (5) we have

$$
\begin{aligned}
M_{1}(G, x) & =\sum_{s r \in E(G)} x^{[d g r(s)+d g r(r)]} \\
M_{1}(K, x) & =\sum_{s r \in E_{1}} x^{[d g r(s)+d g r(r)]}+\sum_{s r \in E_{2}} x^{[d g r(s)+d g r(r)]}+\sum_{s r \in E_{3}} x^{[d g r(s)+d g r(r)]} \\
& +\sum_{s r \in E_{4}} x^{[d g r(s)+d g r(r)]}+\sum_{s r \in E_{5}} x^{[d g r(s)+d g r(r)]}+\sum_{s r \in E_{6}} x^{[d g r(s)+d g r(r)]} \\
M_{1}(K, x) & =\sum_{s r \in E_{1}} x^{10}+\sum_{s r \in E_{2}} x^{13}+\sum_{s r \in E_{3}} x^{14}+\sum_{s r \in E_{4}} x^{16}+\sum_{s r \in E_{5}} x^{17}+\sum_{s r \in E_{6}} x^{18} \\
& =\left|E_{1}\right| x^{10}+\left|E_{2}\right| x^{13}+\left|E_{3}\right| x^{14}+\left|E_{4}\right| x^{16}+\left|E_{5}\right| x^{17}+\left|E_{6}\right| x^{18} \\
& =4 x^{10}+8 x^{13}+(4 p+4 q-8) x^{14}+(2 p+2 q+4) x^{16} \\
& +(4 p+4 q-8) x^{17}+(6 p q-5 p-5 q+4) x^{18} \\
M_{2}(G, x) & =\sum_{s r \in E(G)} x^{[d g r(s) \times d g r(r)]} \\
M_{2}(K, x) & =\sum_{s r \in E_{1}} x^{[d g r(s) \times d g r(r)]}+\sum_{s r \in E_{2}} x^{[d g r(s) \times d g r(r)]}+\sum_{s r \in E_{3}} x^{[d g r r(s) \times d g r(r)]} \\
& +\sum_{s r \in E_{4}} x^{[d g r(s) \times d g r(r)]}+\sum_{s r \in E_{5}} x^{[d g r(s) \times d g r(r)]}+\sum_{s r \in E_{6}} x^{[d g r(s) \times d g r(r)]} \\
& =\sum_{s r \in E_{1}} x^{25}+\sum_{s r \in E_{2}} x^{40}+\sum_{s r \in E_{3}} x^{48}+\sum_{s r \in E_{4}} x^{64}+\sum_{s r \in E_{5}} x^{72}+\sum_{s r \in E_{6}} x^{81} \\
& =\left|E_{1}\right| x^{25}+\left|E_{2}\right| x^{40}+\left|E_{3}\right| x^{48}+\left|E_{4}\right| x^{64}+\left|E_{5}\right| x^{72}+\left|E_{6}\right| x^{81} \\
& =4 x^{25}+8 x^{40}+(4 p+4 q-8) x^{48}+(2 p+2 q+4) x^{64} \\
& +(4 p+4 q-8) x^{72}+(6 p q-5 p-5 q+4) x^{81}
\end{aligned}
$$




\subsection{Methodology and Results of GTUC $[p, q],(p, q \geq 1)$ Nanotube Formulas}

For the Nanotube GTUC $[p, q],(p, q \geq 1)$, we know that the number of vertices in GTUC $[p, q]$ are $4 p(q+1)$ and the number of edges are $6 p q+5 p$. The edge set can be partitioned into the following four disjoint sets:

$$
\begin{aligned}
& E_{1}(\operatorname{GTUC}[p, q])=\{s r \in E(\operatorname{GTUC}[p, q]) \mid \operatorname{dgr}(s)=6, \operatorname{dg} r(r)=8\} \\
& E_{2}(\operatorname{GTUC}[p, q])=\{\operatorname{sr} \in E(\operatorname{GTUC}[p, q]) \mid \operatorname{dgr}(s)=8, \operatorname{dgr}(r)=8\} \\
& E_{3}(\operatorname{GTUC}[p, q])=\{\operatorname{sr} \in E(\operatorname{GTUC}[p, q]) \mid \operatorname{dgr}(s)=8, \operatorname{dg} r(r)=9\} \\
& E_{4}(\operatorname{GTUC}[p, q])=\{\operatorname{sr} \in E(\operatorname{GTUC}[p, q]) \mid \operatorname{dgr}(s)=9, \operatorname{dgr}(r)=9\}
\end{aligned}
$$

The cardinality of edges in $E_{1}(\operatorname{GTUC}[p, q])$ are $4 p$, in $E_{2}(\operatorname{GTUC}[p, q])$ are $2 p$, in $E_{3}(\operatorname{GTUC}[p, q])$ are $4 p$ and in $E_{4}(G T U C[p, q])$ are $6 p q-5 p$. The representatives of these edge set partitions are shown in Figure 6 in which red, green, blue and black edges are the edges belong to $E_{1}(\operatorname{GTUC}[p, q])$, $E_{2}(\operatorname{GTUC}[p, q]), E_{3}(\operatorname{GTUC}[p, q])$ and $E_{4}(G T U C[p, q])$ respectively. Now using Equations (1)-(5), we have

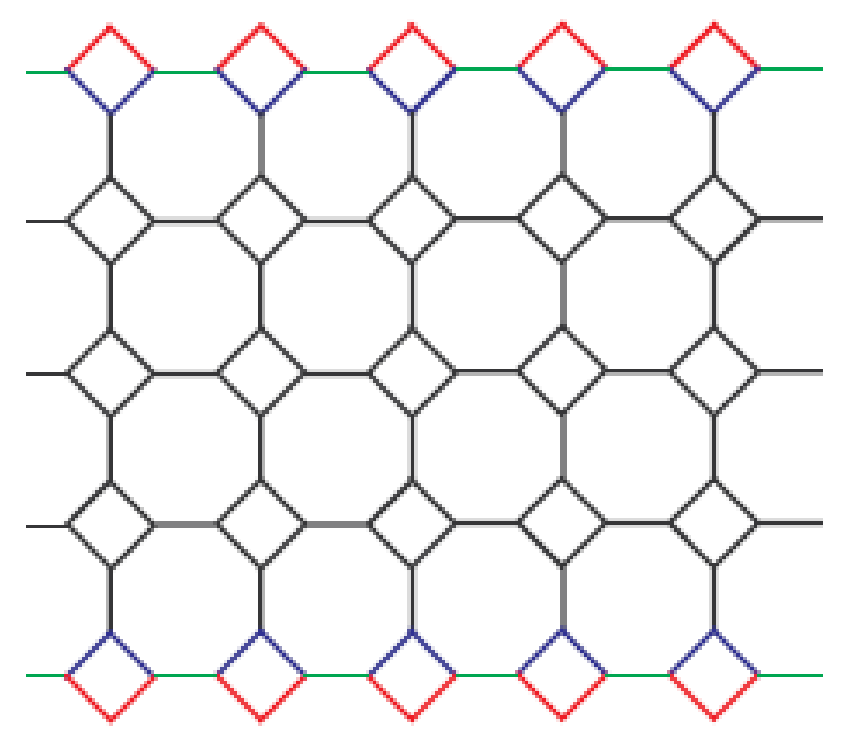

Figure 6. Nanotube $T U C_{4} C_{8}(R)[p, q]$ Nanotube with $p=5$ and $q=4$.

\section{- Hyper Zagreb index of $G T U C[p, q],(p, q \geq 1)$ Nanotube}

Let $G=\operatorname{GTUC}[p, q]$. Now using Equation (1), we have

$$
\begin{aligned}
H M(G) & =\sum_{s r \in E(G)}[\operatorname{dgr}(s)+\operatorname{dg} r(r)]^{2} \\
H M(G) & =\sum_{s r \in E_{1}}[\operatorname{dg} r(s)+\operatorname{dg} r(r)]^{2}+\sum_{s r \in E_{2}}[\operatorname{dg} r(s)+\operatorname{dg} r(r)]^{2} \\
& +\sum_{s r \in E_{3}}[\operatorname{dg} r(s)+\operatorname{dg} r(r)]^{2}+\sum_{s r \in E_{4}}[\operatorname{dgr}(s)+\operatorname{dg} r(r)]^{2} \\
& =14^{2}\left|E_{1}\right|+16^{2}\left|E_{2}\right|+17^{2}\left|E_{3}\right|+18^{2}\left|E_{4}\right| \\
& =196(4 p)+256(2 p)+289(4 p)+324(6 p q-5 p) \\
& =1944 p q+832 p
\end{aligned}
$$


- Multiple Zagreb indices of GTUC $[p, q],(p, q \geq 1)$ Nanotube

Let $G=\operatorname{GTUC}[p, q]$. Now using Equations (2) and (3) we have

$$
\begin{aligned}
P M_{1}(G) & =\prod_{s r \in E(G)}[\operatorname{dg} r(s)+\operatorname{dg} r(r)] \\
P M_{1}(G) & =\prod_{s r \in E_{1}}[\operatorname{dgr}(s)+\operatorname{dg} r(r)] \times \prod_{s r \in E_{2}}[\operatorname{dgr}(s)+\operatorname{dg} r(r)] \\
& \times \prod_{s r \in E_{3}}[\operatorname{dgr} r(s)+\operatorname{dg} r(r)] \times \prod_{s r \in E_{4}}[\operatorname{dgr}(s)+\operatorname{dg} r(r)] \\
& =14^{\left|E_{1}\right|} \times 16^{\left|E_{2}\right|} \times 17^{\left|E_{3}\right|} \times 18^{\left|E_{4}\right|} \\
& =14^{(4 p)} \times 16^{(2 p)} \times 17^{(4 p)} \times 18^{(6 p q-5 p)} \\
P M_{2}(G) & =\prod_{s r \in E(G)}[\operatorname{dgr}(s) \times \operatorname{dg} r(r)] \\
P M_{2}(G) & =\prod_{s r \in E_{1}}[\operatorname{dgr}(s) \times \operatorname{dgr}(r)] \times \prod_{s r \in E_{2}}[\operatorname{dgr}(s) \times \operatorname{dgr}(r)] \\
& \times \prod_{s r \in E_{3}}[\operatorname{dgr}(s) \times \operatorname{dgr}(r)] \times \prod_{s r \in E_{4}}[\operatorname{dgr}(s) \times \operatorname{dgr}(r)] \\
& =48^{\left|E_{1}\right|} \times 64^{\left|E_{2}\right|} \times 72^{\left|E_{3}\right|} \times 81^{\left|E_{4}\right|} \\
& =48^{(4 p)} \times 64^{(2 p)} \times 72^{(4 p)} \times 81^{(6 p q-5 p)}
\end{aligned}
$$

- Zagreb polynomials of $G T U C[p, q],(p, q \geq 1)$ Nanotube

Let $G=G T U C[p, q]$. Now using Equations (4) and (5) we have

$$
\begin{aligned}
& M_{1}(G, x)=\sum_{s r \in E(G)} x^{[\operatorname{dgr}(s)+\operatorname{dgr}(r)]} \\
& M_{1}(G, x)=\sum_{s r \in E_{1}} x^{[\operatorname{dgr}(s)+d g r(r)]}+\sum_{s r \in E_{2}} x^{[\operatorname{dgr} r(s)+\operatorname{dgr}(r)]} \\
& +\sum_{s r \in E_{3}} x^{[\operatorname{dgr}(s)+\operatorname{dgr}(r)]}+\sum_{s r \in E_{4}} x^{[\operatorname{dgr} r(s)+\operatorname{dgr}(r)]} \\
& =\sum_{s r \in E_{1}} x^{14}+\sum_{s r \in E_{2}} x^{16}+\sum_{s r \in E_{3}} x^{17}+\sum_{s r \in E_{4}} x^{18} \\
& M_{1}(G, x)=\left|E_{1}\right| x^{14}+\left|E_{2}\right| x^{16}+\left|E_{3}\right| x^{17}+\left|E_{4}\right| x^{18} \\
& =(4 p) x^{14}+(2 p) x^{16}+(4 p) x^{17}+(6 p q-5 p) x^{18} \\
& M_{2}(G, x)=\sum_{s r \in E(G)} x^{[\operatorname{dgr}(s) \times \operatorname{dgr} r(r)]} \\
& M_{2}(G, x)=\sum_{s r \in E_{1}} x^{[\operatorname{dgr}(s) \times \operatorname{dgr}(r)]}+\sum_{s r \in E_{2}} x^{[\operatorname{dgr}(s) \times \operatorname{dgr}(r)]} \\
& +\sum_{s r \in E_{3}} x^{[\operatorname{dgr} r(s) \times \operatorname{dgr}(r)]}+\sum_{s r \in E_{4}} x^{[\operatorname{dgr} r(s) \times \operatorname{dgr}(r)]} \\
& =\sum_{s r \in E_{1}} x^{48}+\sum_{s r \in E_{2}} x^{64}+\sum_{s r \in E_{3}} x^{72}+\sum_{s r \in E_{4}} x^{81} \\
& =\left|E_{1}\right| x^{48}+\left|E_{2}\right| x^{64}+\left|E_{3}\right| x^{72}+\left|E_{4}\right| x^{81} \\
& =(4 p) x^{48}+(2 p) x^{64}+(4 p) x^{72}+(6 p q-5 p) x^{81}
\end{aligned}
$$




\section{Comparisons and Discussion}

- $\quad$ Firstly, we have obtained some indices of $H_{A} C_{5} C_{7}[p, q]$ Nanotube for any $p$ and $q$. Now from Table 2, it can be seen that all indices are in increasing order as the values of $p, q$ increase. Finally, we depicted the the graphical representation of $H_{A} C_{5} C_{7}[p, q]$ Nanotube for hyper Zagreb index, first and second multiple Zagreb index in Figure 7 and for first and second Zagreb polynomial in Figure 8.

Table 2. Comparison of all indices for $\mathrm{HAC}_{5} C_{7}[p, q]$ Nanotube.

\begin{tabular}{cccc}
\hline$[\boldsymbol{p}, \boldsymbol{q}]$ & $\boldsymbol{H M}(\boldsymbol{G})$ & $\boldsymbol{P M}_{\mathbf{1}}(\boldsymbol{G})$ & $\boldsymbol{P M}_{\mathbf{2}}(\boldsymbol{G})$ \\
\hline$[1,1]$ & 2796 & $2.11 \times 10^{11}$ & $3.4 \times 10^{15}$ \\
{$[2,2]$} & 13,368 & $3.31 \times 10^{25}$ & $4.5 \times 10^{28}$ \\
{$[3,3]$} & 31,716 & $4.21 \times 10^{55}$ & $6.61 \times 10^{62}$ \\
{$[4,4]$} & 57,840 & $6.57 \times 10^{95}$ & $8.72 \times 10^{98}$ \\
\hline
\end{tabular}

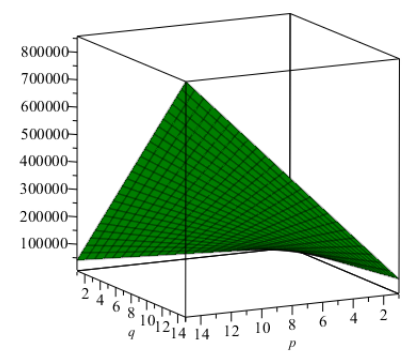

(a)

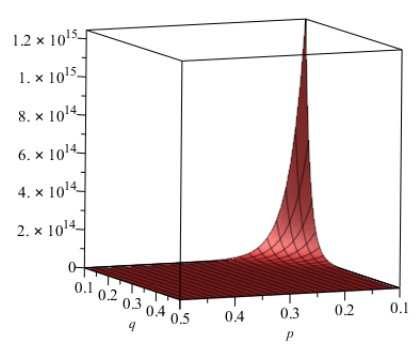

(b)

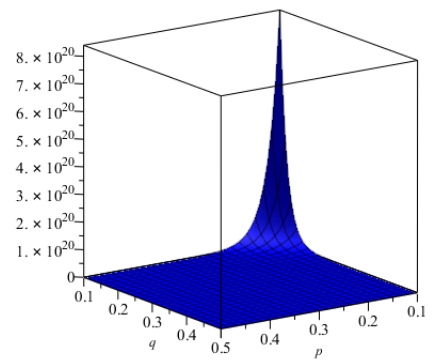

(c)

Figure 7. (a) Hyper Zagreb index; (b) First multiple Zagreb index; (c) Second multiple Zagreb index.

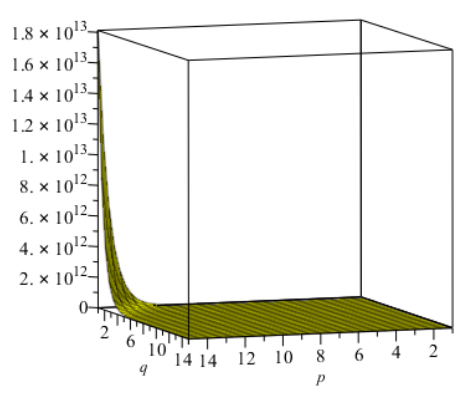

(a)

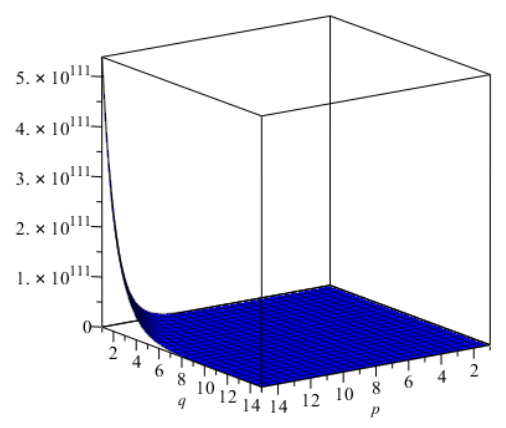

(b)

Figure 8. (a) First Zagreb polynomial; (b) Second multiple Zagreb polynomial.

- Secondly, we have worked out many indices of $H_{A} C_{5} C_{6} C_{7}[p, q]$ Nanotube for each $p$ and $q$. Now from Table 3, we can easily see that all indices are in increasing order as the values of $p, q$ increase. Finally, we gave the the graphical representation of $H A C_{5} C_{6} C_{7}[p, q]$ Nanotube for hyper Zagreb index, first and second multiple Zagreb index in Figure 9 and for first and second Zagreb polynomial in Figure 10. 
Table 3. Comparison of all indices for $\mathrm{HAC}_{5} \mathrm{C}_{6} \mathrm{C}_{7}[p, q]$ Nanotube.

\begin{tabular}{cccc}
\hline$[p, q]$ & $\boldsymbol{H M}(\boldsymbol{G})$ & $\boldsymbol{P M}_{\mathbf{1}}(\boldsymbol{G})$ & $\boldsymbol{P M}_{\mathbf{2}}(\boldsymbol{G})$ \\
\hline$[1,1]$ & 5522 & $3.4 \times 10^{13}$ & $4.5 \times 10^{16}$ \\
{$[2,2]$} & 26,596 & $5.3 \times 10^{26}$ & $6.5 \times 10^{31}$ \\
{$[3,3]$} & 63,222 & $6.31 \times 10^{65}$ & $7.62 \times 10^{72}$ \\
{$[4,4]$} & 115,400 & $7.57 \times 10^{98}$ & $9.82 \times 10^{99}$ \\
\hline
\end{tabular}

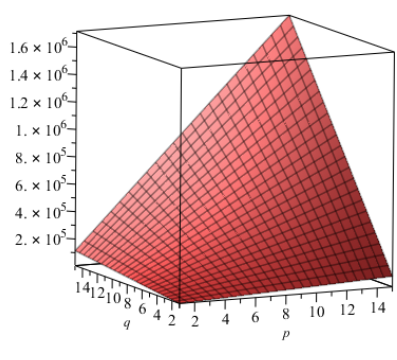

(a)

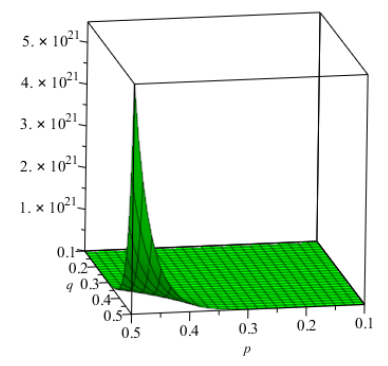

(b)

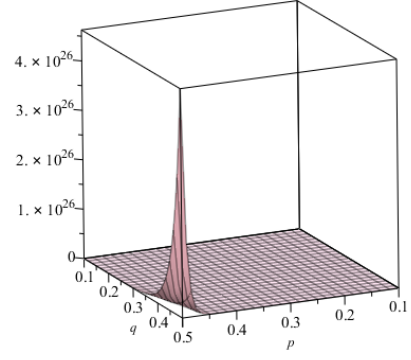

(c)

Figure 9. (a) Hyper Zagreb index; (b) First multiple Zagreb index; (c) Second multiple Zagreb index.

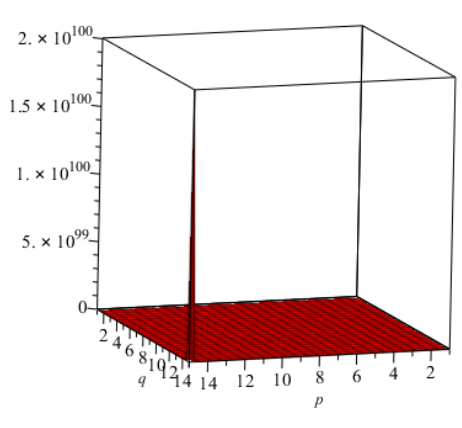

(a)

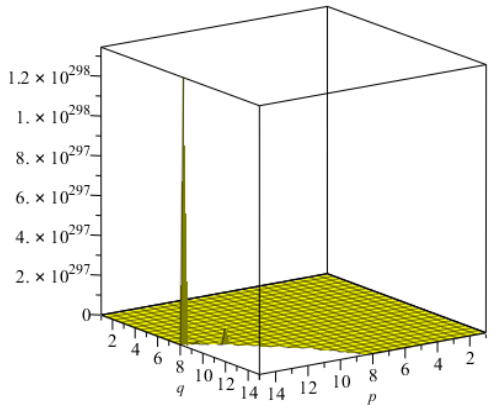

(b)

Figure 10. (a) First Zagreb polynomial; (b) Second multiple Zagreb polynomial.

- $\quad$ Now, we have worked out various indices of $\operatorname{KTUC}[p, q],(p, q \geq 1)$ Nanotorus with different $p$ and $q$. Now from Table 4 , we have that each index increases with the values of $p, q$ increasing. Finally, we depicted the the graphical representation of $\operatorname{KTUC}[p, q],(p, q \geq 1)$ Nanotorus for hyper Zagreb index, first and second multiple Zagreb index in Figure 11 and for first and second Zagreb polynomial in Figure 12.

Table 4. Comparison of all indices for $\operatorname{KTUC}[p, q],(p, q \geq 1)$ Nanotorus.

\begin{tabular}{cccc}
\hline$[\boldsymbol{p}, \boldsymbol{q}]$ & $\boldsymbol{H M}(\boldsymbol{G})$ & $\boldsymbol{P M}_{\mathbf{1}}(\boldsymbol{G})$ & $\boldsymbol{P M}_{\mathbf{2}}(\boldsymbol{G})$ \\
\hline$[1,1]$ & 2996 & $3.2 \times 10^{12}$ & $4.5 \times 10^{18}$ \\
{$[2,2]$} & 11,296 & $4.6 \times 10^{27}$ & $5.7 \times 10^{30}$ \\
{$[3,3]$} & 22,680 & $6.8 \times 10^{58}$ & $6.21 \times 10^{61}$ \\
{$[4,4]$} & 37,952 & $8.7 \times 10^{96}$ & $7.8 \times 10^{97}$ \\
\hline
\end{tabular}




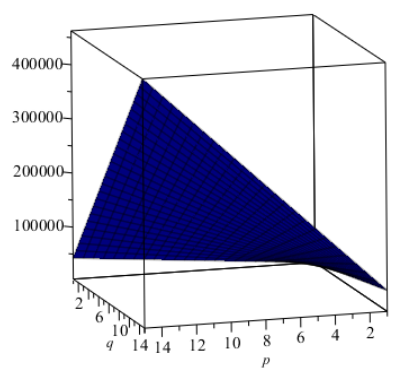

(a)

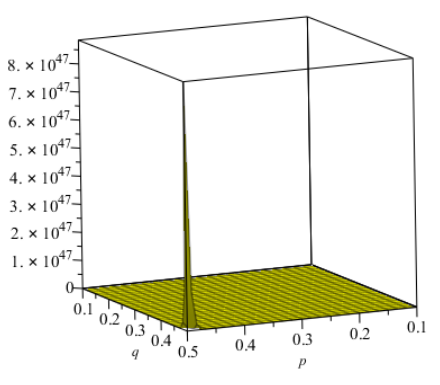

(b)

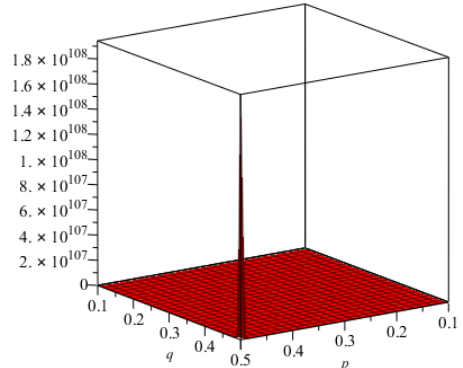

(c)

Figure 11. (a) Hyper Zagreb index; (b) First multiple Zagreb index; (c) Second multiple Zagreb index.

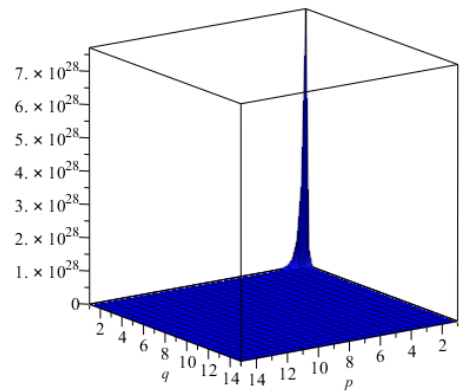

(a)

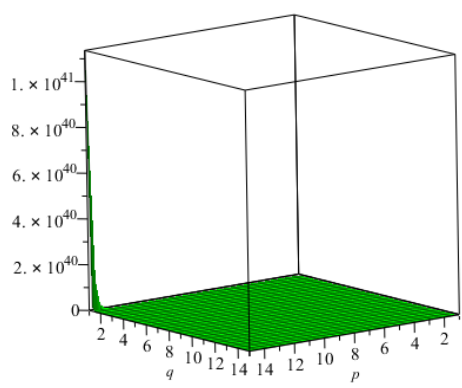

(b)

Figure 12. (a) First Zagreb polynomial; (b) Second multiple Zagreb polynomial.

- $\quad$ At the end of this section, we have computed substantial indices of GTUC $[p, q],(p, q \geq 1)$ Nanotube for different values of $p, q$. Now from Table 5, it can be seen that all indices are in increasing order as the values of $p, q$ increase. We also provided the the graphical representation of GTUC $[p, q],(p, q \geq 1)$ Nanotube for hyper Zagreb index, first and second multiple Zagreb index in Figure 13 and for first and second Zagreb polynomial in Figure 14.

Table 5. Comparison of all indices for GTUC $[p, q],(p, q \geq 1)$ Nanotube.

\begin{tabular}{cccc}
\hline$[p, q]$ & $\boldsymbol{H M}(\boldsymbol{G})$ & $\boldsymbol{P M}_{\mathbf{1}}(\boldsymbol{G})$ & $\boldsymbol{P M}_{\mathbf{2}}(\boldsymbol{G})$ \\
\hline$[1,1]$ & 2776 & $1.2 \times 10^{14}$ & $2.3 \times 10^{15}$ \\
{$[2,2]$} & 9440 & $3.6 \times 10^{21}$ & $4.5 \times 10^{25}$ \\
{$[3,3]$} & 19,992 & $5.8 \times 10^{53}$ & $5.23 \times 10^{51}$ \\
{$[4,4]$} & 34,432 & $7.7 \times 10^{95}$ & $6.7 \times 10^{96}$ \\
\hline
\end{tabular}

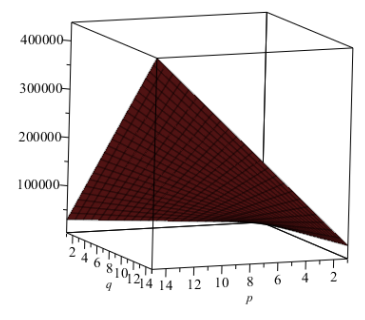

(a)

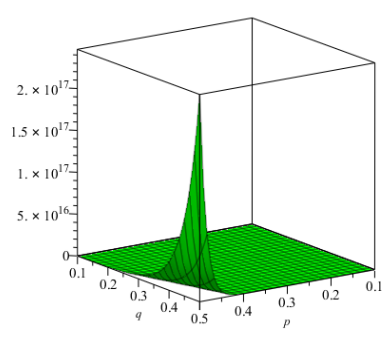

(b)

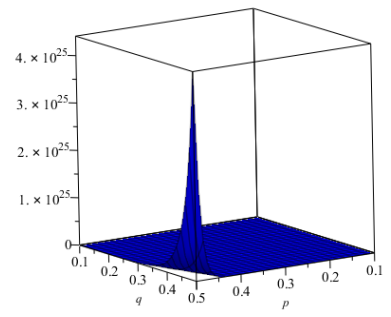

(c)

Figure 13. (a) Hyper Zagreb index; (b) First multiple Zagreb index; (c) Second multiple Zagreb index. 


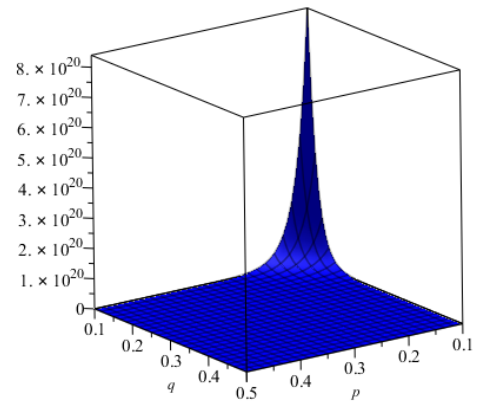

(a)

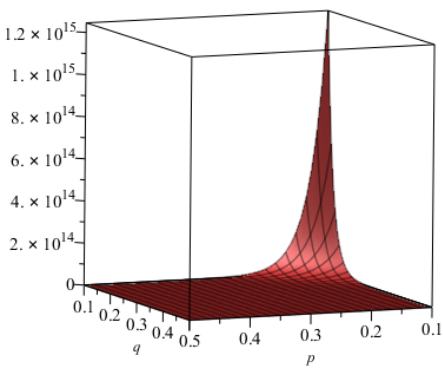

(b)

Figure 14. (a) First Zagreb polynomial; (b) Second multiple Zagreb polynomial.

\section{Conclusions}

In this paper, we computed various topological indices of Nanotubes. More precisely, we determined second multiple Zagreb index $P M_{2}(G)$, hyper-Zagreb index $H M(G)$, first multiple Zagreb index $P M_{1}(G)$, and Zagreb polynomials $M_{1}(G, x), M_{2}(G, x)$ for certain Nanotubes. We conclude that the the Zagreb indices are in increasing order as the values of $p, q$ increase. In addition, the hyper Zagreb index gives a decent connection to the security of nonstructural objects and the stretched pharmacies, and for processing the strain vitality of Nanotubes. The first and second Zagreb polynomials are helpful to find the features of $\pi$-electron energy of the microscopic particles in the inner part of Nanostructural objects.

Author Contributions: Z. Shao contribute for conceptualization, designing the experiments, funding and analyzed the data curation. M.K. Siddiqui contribute for supervision, methodology, validation, project administration and formal analysing. M.H. Muhammad contribute for performed experiments, resources, software, some computations and wrote the initial draft of the paper which were investigated and approved by $\mathrm{Z}$. Shao and M.K. Siddiqui and wrote the final draft. All authors read and approved the final version of the paper.

Funding: This research work is supported by Applied Basic Research (Key Project) of Sichuan Province under Grant No. 2017JY0095.

Conflicts of Interest: The authors declare no conflict of interest.

\section{References}

1. Naji, A.M.; Soner, N.D.; Gutman, I. On leap Zagreb indices of graphs. Commun. Comb. Optim. 2017, 2, 99-117.

2. Shao, Z.; Wu, P.; Gao, Y.; Gutman, I.; Zhang, X. On the maximum ABC index of graphs without pendent vertices. Appl. Math. Comput. 2017, 315, 298-312. [CrossRef]

3. Shao, Z.; Wu, P.; Zhang, X.; Dimitrov, D.; Liu, J. On the maximum ABC index of graphs with prescribed size and without pendent vertices. IEEE Access 2018, 6, 27604-27616. [CrossRef]

4. Wiener, H. Structural determination of paraffin boiling points. J. Am. Chem. Soc. 1947, 69, 17-20. [CrossRef] [PubMed]

5. Dobrynin, A.A.; Entringer, R.; Gutman, I. Wiener index of trees: Theory and applications. Acta Appl. Math. 2001, 66, 211-249. [CrossRef]

6. Gutman, I.; Trinajstic, N. Graph theory and molecular orbitals. Total $\phi$-electron energy of alternant hydrocarbons. Chem. Phys. Lett. 1972, 17, 535-538. [CrossRef]

7. Shirdel, G.H.; RezaPour, H.; Sayadi, A.M. The hyper-Zagreb Index of Graph Operations. Iran. J. Math. Chem. 2013, 4, 213-220.

8. Ghorbani, M.; Azimi, N. Note on multiple Zagreb indices. Iran. J. Math. Chem. 2012, 3, 137-143.

9. Eliasi, M.; Iranmanesh, A.; Gutman, I. Multiplicative version of first Zagreb index. MATCH Commun. Math. Comput. Chem. 2012, 68, 217-230.

10. Furtula, B.; Gutman, I.; Dehmer, M. On structure-sensitivity of degree-based topological indices. Appl. Math. Comput. 2013, 219, 8973-8978. [CrossRef] 
11. Gutman, I.; Das, K.C. Some Properties of the Second Zagreb Index. MATCH Commun. Math. Comput. Chem. 2004, 50, 103-112.

12. Farahani, M.R. The hyper zegreb index of TUSC $C_{4} C_{8}(S)$ Nanotubes. Int. J. Eng. Technol. Res. 2015, 3, 1-6.

13. Hayat, S.; Imran, M. Computation of topological indices of certain networks. Appl. Math. Comput. 2014, 240, 213-228. [CrossRef]

14. Iranmanesh, A.; Alizadeh, Y. Computing wiener index of $H A C_{5} C_{7}[p, q]$ Nanotubes by gap program. Iran. J. Math. Sci. Inform. 2008, 3, 1-12.

15. Iranmanesh, A.; Zeraatkar, M. Computing ga index of $H A C_{5} C_{7}[p, q]$ and $H A C_{5} C_{6} C_{7}[p, q]$ Nanotubes. Optoelectron. Adv. Mater.-Rapid Commun. 2011, 5, 790-792.

16. Gao, W.; Siddiqui, M.K.; Naeem, M.; Rehman, N.A. Topological Characterization of Carbon Graphite and Crystal Cubic Carbon Structures. Molecules 2017, 22, 1496. [CrossRef] [PubMed]

17. Bača, M.; Horváthová, J.; Mokrišová, M.; Suhányiová, A. On topological indices of fullerenes. Appl. Math. Comput. 2015, 251, 154-161. [CrossRef]

18. Bača, M.; Horváthová, J.; Mokrišová, M.; Semanicová-Fenovcíková, A.; Suhányiová, A. On topological indices of carbon Nanotube network. Can. J. Chem. 2015, 93, 1-4. [CrossRef]

19. Gao, W.; Farahani, M.R.; Siddiqui, M.K.; Jamil, M.K. On the First and Second Zagreb and First and Second Hyper-Zagreb Indices of Carbon Nanocones $\mathrm{CNC}_{k}[n]$. J. Comput. Theor. Nanosci. 2016, 13, 7475-7482. [CrossRef]

20. Gao, W.; Farahani, M.R.; Jamil, M.K.; Siddiqui, M.K. The Redefined First, Second and Third Zagreb Indices of Titania Nanotubes $\mathrm{TiO}_{2}[m, n]$. Open Biotechnol. J. 2016, 10, 272-277. [CrossRef]

21. Gao, W.; Siddiqui, M.K.; Imran, M.; Jamil, M.K.; Farahani, M.R. Forgotten Topological Index of Chemical Structure in Drugs. Saudi Pharm. J. 2016, 24, 258-267. [CrossRef] [PubMed]

22. Imran, M.; Hayat, S.; Mailk, M.Y.H. On topological indices of certain interconnection networks. Appl. Math. Comput. 2014, 244, 936-951. [CrossRef]

23. Hayat, S.; Imran, M. Computation of certain topological indices of Nanotubes covered by $C_{5}$ and $C_{7}$. J. Comput. Theor. Nanosci. 2015, 12, 1-9.

24. Imran, M.; Siddiqui, M.K.; Naeem, M.; Iqbal, M.A. On Topological Properties of Symmetric Chemical Structures. Symmetry 2018, 10, 173. [CrossRef]

25. Siddiqui, M.K.; Gharibi, W. On Zagreb Indices, Zagreb Polynomials of Mesh Derived Networks. J. Comput. Theor. Nanosci. 2016, 13, 8683-8688. [CrossRef]

26. Siddiqui, M.K.; Imran, M.; Ahmad, A. On Zagreb indices, Zagreb polynomials of some nanostar dendrimers. Appl. Math. Comput. 2016, 280, 132-139. [CrossRef]

27. Siddiqui, M.K.; Naeem, M.; Rahman, N.A.; Imran, M. Computing topological indicesof certain networks. J. Optoelectron. Adv. Mater. 2016, 18, 884-892.

28. Mahmiani, A.; Iranmanesh, A. Edge-Szeged Index of $H_{A} C_{5} C_{7}[r, p]$ Nanotube. MATCH Commun. Math. Comput. Chem. 2009, 62, 397-417.

29. Yazdani, J.; Bahrami, A. Padmakar-Ivan, Omega and Sadhana Polynomial of $H A C_{5} C_{6} C_{7}$ Nanotubes. Dig. J. Nanomater. Biostruct. 2009, 4, 507-517.

30. Ashrafi, A.R.; Dosli, T.; Saheli, M. The eccentric connectivity index of $\mathrm{TUC}_{4} \mathrm{C}_{8}(\mathrm{R})$ Nanotubes. MATCH Commun. Math. Comput. Chem. 2011, 65, 221-230.

31. Ghorbani, M. Computing $A B C_{4}$ index of nanostar dendrimers. Optoelectron. Adv. Mater.-Rapid Commun. 2010, 4, 1419-1422.

(C) 2018 by the authors. Licensee MDPI, Basel, Switzerland. This article is an open access article distributed under the terms and conditions of the Creative Commons Attribution (CC BY) license (http://creativecommons.org/licenses/by/4.0/). 